\title{
Promoting workforce excellence: formation and relevance of vocational identity for vocational educational training
}

\author{
Viola Katharina Klotz ${ }^{1 *}$, Stephen Billett ${ }^{2}$ and Esther Winther ${ }^{1}$
}

\author{
* Correspondence: \\ Viola.Klotz@wiwi.upb.de \\ ${ }^{1}$ Chair of Business and Human \\ Resource Education, University of \\ Paderborn, Warburger Straße 100, \\ D-33098, Paderborn, Germany \\ Full list of author information is \\ available at the end of the article
}

\begin{abstract}
Vocational learning comprises more than factual knowledge and procedures; the development of a vocational identity is a key aspect and outcome of vocational education provisions and assumed to play an integral role in how students learn and perform. Despite the salience of vocational identity however, the processes that contribute to its formation are far from fully understood. It is unclear whether and which elements of vocational education and training provision shape this process and if and to what degree forms of identity really support the actual vocational performance of a vocational learner. This study seeks to provide deeper understanding of the circumstances that enable different forms of identity to develop and how they direct learning and workplace effort. Using structural equation modeling with data from 504 vocational learners and correlation analysis with data from 187 industrial apprentices, this article proposes a model to account for key influences and the impacts of vocational identity formation for the commercial sector. The results indicate that vocational identity mediates and is closely aligned to the development of vocational engagement and competence. A free career choice and the provision of maximal functional integration into operating processes at the workplace are key factors underlying identity formation.
\end{abstract}

Keywords: Workplace learning; Vocational identity; Competence

\section{苗

\section{Background}

The purposes of vocational education and training (VET) go beyond developing the technical capacities required to perform an occupation effectively or securing students' employment (Baethge et al. 2009; Renold 2009); they extend to the formation of students' identity within and attachment to an occupation, as well as their integration into society through that identity (Baethge and Arends 2009; Drexel 2005). A characteristic feature of the German initial vocational training system, for example, is that those undertaking apprenticeships develop strong occupational ties and form an identity associated with that occupation, rather than loyalties to a specific company or employer (Haasler 2007; Rauner 2007). Skilled workers' vocational identity is a crucial component of the German workforce, central to its ability to remain successful in an era of unprecedented global competition, because of its effects on vocational capacities, skill performance, and quality (Rauner 1999; Skorikov and Vondracek 2007). Without vocational identities, workers' abilities to plan, execute, and monitor their work activities autonomously would be

(c) 2014 Klotz et al.; licensee Springer. This is an Open Access article distributed under the terms of the Creative Commons Attribution License (http://creativecommons.org/licenses/by/2.0), which permits unrestricted use, distribution, and reproduction in any medium, provided the original work is properly credited. 
far less likely. In turn, vocational identity guides workers' practices during the course of completing complex, demanding tasks, and it offers a sustainable source of intrinsic motivation that directs and secures individual engagement with the vocation (Rauner 1999). Thus, for both institutional and personal purposes, developing strong vocational identities is an implicit goal of German vocational education; in Switzerland, it is even explicitly included in the stated learning outcomes for the vocational education system (\$50 BBG 2002).

Despite the salience of workplace and vocational identity however, the processes that contribute to its formation are far from fully understood. It is unclear whether and which elements of VET provision shape learners' identities and even more unclear whether the desired effects of a strong identity in terms of an enhanced vocational performance actually materialize. To shed light on how these factors and associations contribute to vocational performance, we need an integrative approach to investigate both contextual and psychological factors. Such an inquiry would contribute to deeper understanding of the circumstances that enable different forms of identity to develop and how they affect both learning and workplace effort.

To this end, we first outline the theoretical concepts vocational identity and workplace identity. We then present a background model and a conceptual model, informed by a thorough review of the literature and accounting for major hypotheses about the genesis and effects of vocational identity. Regarding the elements of VET that shape these concepts, our literature review focuses on (1) the effect of a dual versus school-based VET, (2) integration at the workplace, and (3) free career choice; for the effects and alignments of vocational identity, we focus on (4) workplace effort and (5) vocational competence as prerequisites for effectual vocational performance. We then show that associations across occupational environments, together with students' or apprentices' vocational performance, are mediated by fundamental motivational traits associated with vocational and workplace identities. Figure 1 presents our conceptual model graphically.

As a result, we provide a clearer understanding of how vocational learners are motivated to develop such associations. We ask weather government's and employer's expectations

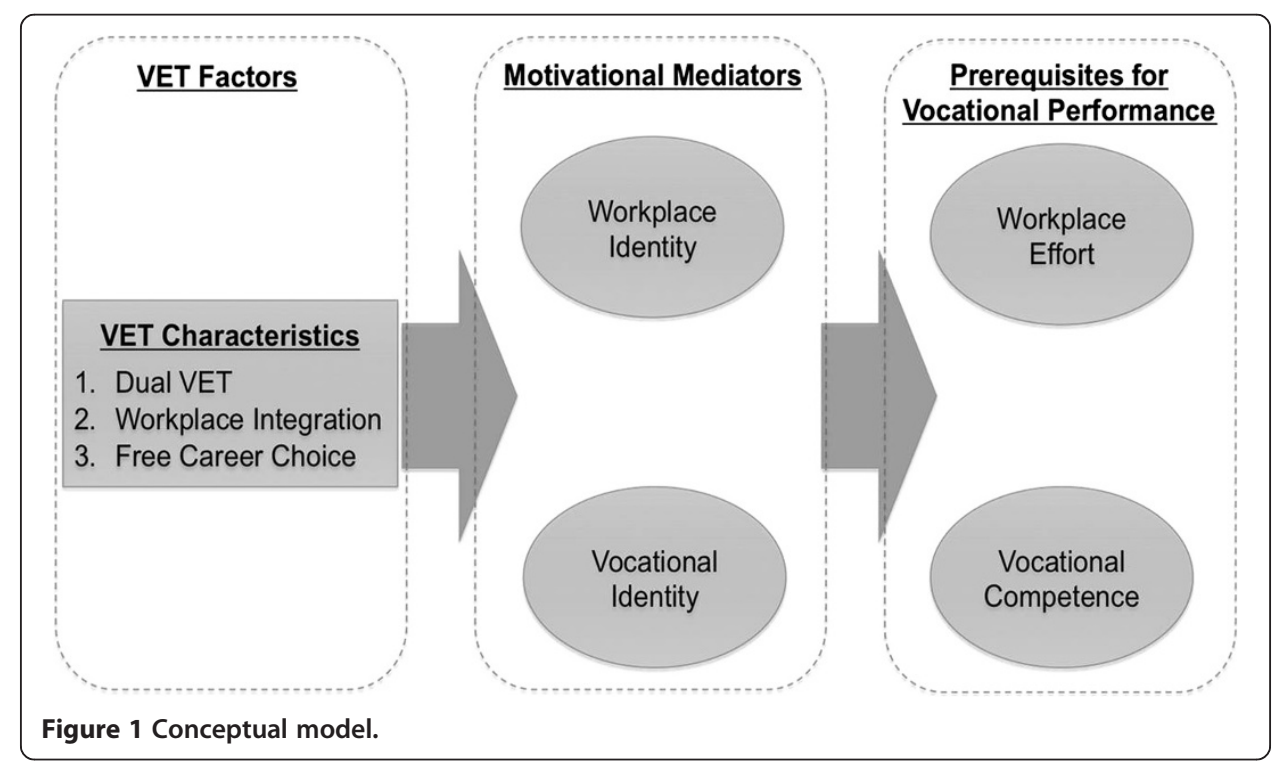


of the German dual VET are realistic and how these expectations can be realized. Accordingly, we consider how students learn (Pellegrino et al. 2001; Shavelson and Ruiz-Primo 2005), how they exercise agency in participating in and learning through work, and on what bases and for what purposes they exercise this agency.

\section{Theoretical conception of vocational identity}

To understand the mechanisms that lead to the formation of vocational identity, we must clarify what is formed and how to measure that formation. Next, we define the terms "vocation" and "identity" to provide a clearer picture of our conception of vocational identity.

Billett (2011) distinguishes an "occupation," which comprises social facts, from the personal elements that individuals come to identify with and assent to as their "vocation." Thus, we acknowledge both occupations and something else that describes people's interests or "calling." In the second sense, vocations might be specified as those activities to which people are drawn (Estola et al. 2003) or "called" (e.g., Dror 1993), which provide lifelong fulfillment through their exercise (Hansen 1994). Separating these two usages is critical to understanding occupational identity (i.e., vocation), in that they imply distinct goals for vocational education and separate measures.

The first term, occupation, refers to institutional, normative, and discourse practices associated with individual identities. Occupations offer examples, which are ordered and valued in particular ways, starting with their origins in historical and social forms (Billett 2011). Accordingly, identifiable societal expectations and factors are associated with people with an occupation, whether as an auto mechanic, nurse, accountant, or industrial clerk. In contemporary terms, the notion of vocation as occupation suggests that VET should be highly responsive to industry expectations, existing standards, and employers' needs, often supported by government interests and economic imperatives. This influence becomes particularly salient when there are either national skill shortages or high levels of unemployment, particularly youth unemployment (Aldrich 1994; Anderson 1998; Butler 2000; Kantor 1986; Renold 2009). During these periods, vocational education is primarily a means to provide effective preparation and a smooth transition for students into the occupational practices needed in society. Governments' typical definition of vocational education thus focuses primarily on developing the capacities needed for particular forms of work (i.e., occupations) in ways that meet societal needs (i.e., demand for skilled labor). Its purposes, forms, and key endorsements appear within and are products of society, that is, institutional facts (Searle 1995).

The second term, vocations, is defined as the individual worker's journey, calling, or personal trajectory (Dewey 1916). The essentially personal phenomenon energizes and directs a person's individual's intentions, activities, and interactions (Estola et al. 2003), even as they continue to be shaped by external factors (e.g., societal standing of the occupation, gendered associations). This view also accounts for the process of learning, which is a person-dependent process. From this perspective, VET functions to secure personal goals and development pathways, thus assisting students in engaging in learning that reflects their aspirations and enables them to realize their full potential.

By combining these views, we propose for this study that vocations are personally directed but also socially derived practices that reflect a person's enduring aspirations 
and interests. They are usually manifested in culturally and historically derived activities that offer value for both the individual and the community (Billett 2011).

Social science has different conceptualizations of identity, focusing on (1) a social identity conceptualization designating a person's position in a social system and (2) a personal identity conceptualization denoting aspects of individual experience rooted in interactions (Côté and Levine 2002). At the level of social identity, the individual is most influenced by cultural factors and social roles, experiencing varying degrees of pressure to fit into an available identity that can be characterized mainly as a vocational habitus (e.g., Bourdieu 1990). This concept corresponds to our understanding of the term "occupation." In contrast, at the level of personal identity, individuals find a fit between their perception of the social world and their own personality (potentials, interests, and desires, often referred to as "aspirations"). A personal identity is therefore affected by social influencing factors, but this relation is pivotally designated by individual personality and how people perceive such external influences (Mead 1934). This identity definition corresponds to our understanding of "vocations." Accordingly, we define "vocational identity" as how people negotiate and align their personality with an occupation's norms and practices or, more precisely, as the fit between an individual's perception of the occupational world and his or her self-perception.

We further propose, in line with Marsh and Shavelson (1985), that the analysis of a person's identity in regard to a specific area or domain (e.g., toward a vocation) is more fruitful than a global identity conception. We acknowledge that the relative salience of identity domains may vary across cultures and socioeconomic contexts but note that several studies confirm that vocational identity development is a priority in adolescence (Kroger 1993; Skorikov and Vondracek 1998, Solomontos-Kountouri and Hurry 2008). In the domain of vocational identity, theoretical and empirical research streams have generally confirmed that two subdomains of vocational identity exist: one referring to the actual vocation in a broad sense and one referring to a person's workplace (also referred to as "organizational identity"; e.g., Cohen 1991; Lee et al. 2000; Wallace 1993). We refer to both conceptions for our research endeavor.

We operationalized the first concept of vocational identity according to our theoretical definition: the fit between a person's perception of the social structures of an occupational world and that person's perception of his or her own personality. To measure this concept, we asked students about the fit between their chosen vocation and their personality (e.g. "My vocation fits me," "My vocation is an integral part of who I am," "I am proud of my vocation"). Workplace identity analogously refers to the perceived fit between a person's sense of self and the workplace's norms and practices. We accordingly asked apprentices if, for example, they feel like a part of their company, if they draw satisfaction from working for it, if they consider their company as fitting to them, and if they are proud to be a part of their company.

\section{Hypotheses: Predictors and impacts of vocational identity}

Our general framework (shown in Figure 2) for analyzing our theoretical conception of vocational identity is based on House's (1977) personality and social structure perspective (PSSP) and its proposed levels of personality, interaction, and social structure. Lempert (2009) transfers the PSSP model to a theoretical model of the formation of vocational 


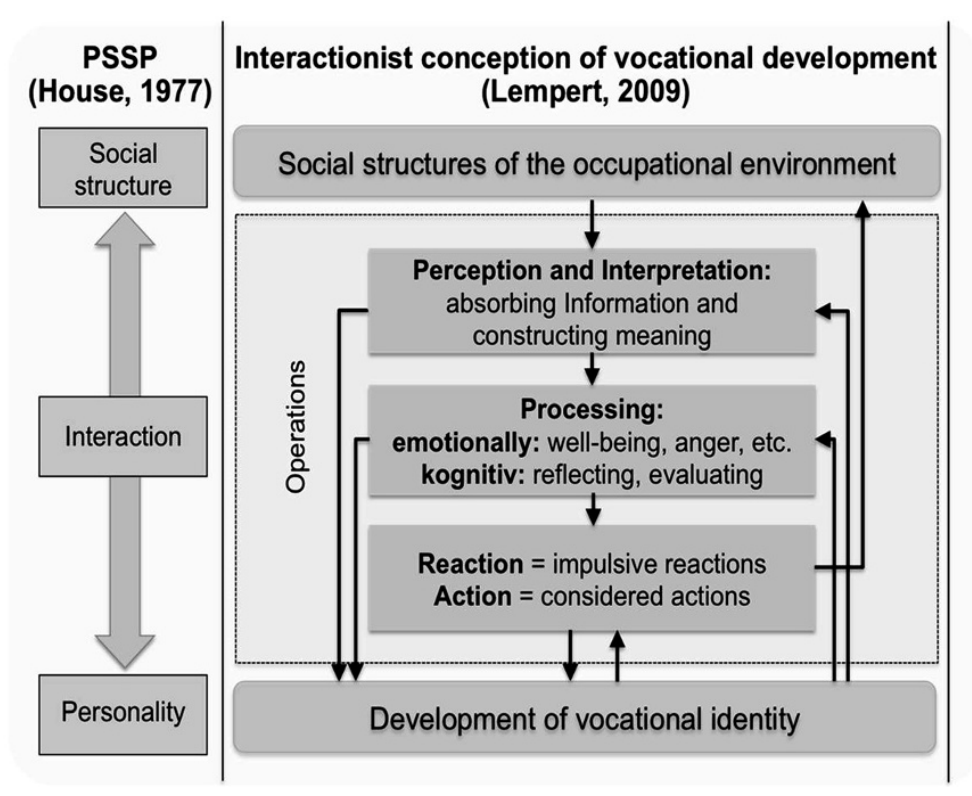

Figure 2 Theoretical framework: levels and operations determining the genesis and effects of vocational identity according to Lempert (2009).

learning, identifying vocational identity as a major aspect of vocational learning. The person interacts with the social structures of the occupational environment ("interaction" here refers to the person's contact and communication with his or her surroundings, comprising several cognitive operations). This interaction is crucially influenced by the person's personality (including cognitive structures), which then influences his or her perception and interpretation of vocational experiences, resulting in differentiated processing of experiences and ultimately reactions (impulsive) or actions (considerate).

According to this model, we regard the process of identity formation as a function of both external (social) and internal (agentic) components, suggesting that both sociological and psychological perspectives are essential for a comprehensive understanding of this concept (Côté and Levine 2002; Lempert 2009). We further assume, in line with this model, that vocational identity affects a person's actions and reactions at the workplace: it influences the person's work results and therefore his or her vocational performance (i.e., "performance" defined, in line with Chomsky (1981), as the outward production of actual events at the workplace). Performance occurs when there is competence as well as possibility and willingness for demonstration (Achtenhagen 2004; Boekaerts 2002).

To identify possible major influences and the effects of vocational identity, we began by designing a conceptual model. Next, we conducted a thorough review of the existing literature in the vocational identity domain. We then formulated five hypotheses and implemented them into one coherent and empirically testable theoretical model (Figure 3). We detail our hypotheses in the following subsections.

Vocational identity is fostered better by dual training than by school-based learning Both blue- and white-collar apprentices in Germany gain work skills through a dual system that comprises both on- and off-the-job components. Off-the-job training is 


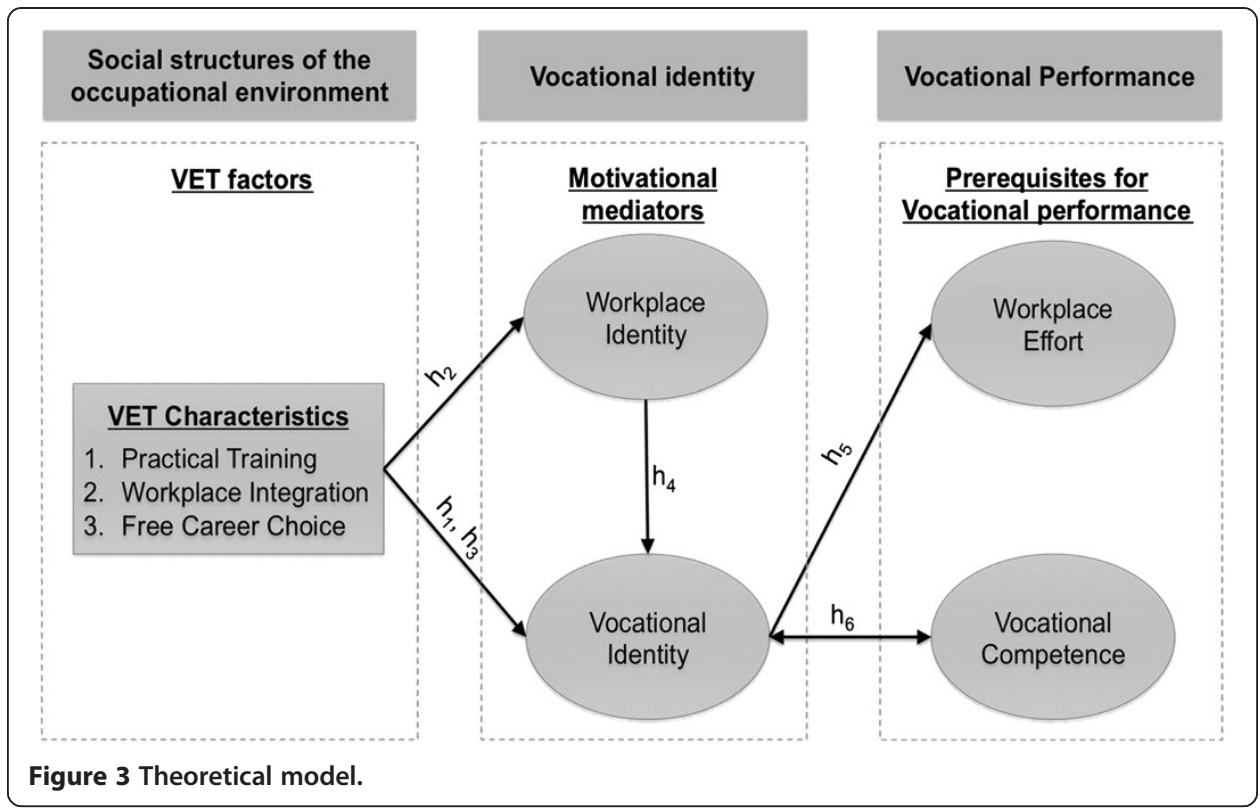

financed by the state, with the aim of developing theoretical knowledge the worker will need in the occupation, in addition to the knowledge gained through a general education. On-the-job preparation entails participation in work activities at a firm, which includes a systematic regimen characterized by adherence to training regulations and interactions with trainers or masters who guide apprentices through the realistic components of the apprenticeship (Ashton and Green 1996; Kutscha 2000). Furthermore, apprenticeships tend to be sensitive to business cycles, such that in 2011, only 51\% of students participated in the dual system, whereas $20 \%$ enrolled in regular vocational schools, and $29 \%$ prepared for regular vocational training in a so-called transitional system, ${ }^{a}$ also organized by vocational schools (BMBF 2012). Because of this trend, we compared the consequences of participating in either dual or school-based training, including the implications for the formation of vocational identity. Kirpal (2006) posits that more positive outcomes derive from dual vocational preparation than from a solely school-based preparation for identity formation; we draw on this proposition and predict that continuous learning at the workplace, such as the learning gained in a dual training, positively influences identity value. We tested this hypothesis using a dummy variable indicating dual or solely school-based training.

\section{Workplace identity is determined by workplace integration}

We define "workplace integration" as the functional integration of apprentices into operating working processes. Individual workplaces feature distinct practice requirements, due to their unique location, clients/customers, services offered, workplace culture, norms, history, and employees. Thus, various firms have unique ways of working and desired outcomes, even if they engage in similar occupations (Billett 2006). Apprentices' workplace experiences, including activities and interactions, influence what they learn, mediated by social interactions with other employees. People who have been invited to participate in work activities and integrated into the work process thus may come to 
identify more with their workplace. Qualitative research affirms the importance of work participation for shaping identities and competencies (Corsten and Lempert 1992; Hartigan-Rogers et al. 2007; Henderson et al. 2007). Newton et al. (2009) find that when workplace environments welcome and support novice nurses, providing them with opportunities for active participation in the work process rather than just observational roles, they contribute richly to learning. Such experiences also should support the formation of workplace identity. Thus, whereas our first hypothesis compared the vocational identity of apprentices undergoing dual vocational versus school-based training, our second hypothesis relates solely to dual vocational apprentices, who have opportunities to experience real-life work, to predict how these experiences influence their workplace identity. To address this issue, we asked apprentices if they felt integrated into all operating processes of their back office.

\section{Vocational identity is enhanced by free career choice}

A vocation in our definition implies a calling; therefore, the ability to choose a particular occupation is critical. In line with Bühler (2007) and Heinemannet al. (2009), we suggest that free vocational choice not only is desirable for its own sake but also can shape the formation of the person's vocational identity. We define "free career choice" as the degree to which the choice of a person for his or her preferred vocation was a voluntary one. Involuntary career choices may be the result of, for example, monetary restrictions, social pressure to choose a certain vocation, or certain forms of discrimination constituting barriers for a person to choose a desired vocation (Lent et al. 2000). To assess this influence, we used the item, "My vocation was my preferred vocation of choice," introduced by Heinemannet al. (2009, p. 10). However, we acknowledge that vocational trajectories also may arise through participation in activities that were not initially enacted or identified by workers as vocational for them but were locally and socially convenient (Billett 2011). For example, Somerville (2006) finds among elder care workers in Australia that though they did not originally intend to pursue this vocation, they became increasingly engaged with their work and developed a strong vocational identity over time.

\section{Workplace effort within VETs is mediated by vocational identity}

Several studies have examined the relationship between forms of vocational and workplace identity. Wallace (1993) cites a corrected average correlation of 45 between the two concepts, and with a meta-analysis, Lee et al. (2000) specify a similar corrected correlation of .45 between occupational commitment and organizational commitment (which we refer to as "vocational identity" and "workplace identity") across 49 samples. However, the causality between these variables remains somewhat unclear; they may even be bidirectional. According to Peiperl and Baruch (1997), in a post-corporate career realm, vocational identity gains potency and serves as a source or predictor of workplace identity. They argue that people decide to become members of an occupation before being employed by a particular employer. Aranya et al. (1981) propose that professional affiliation is both separate from and a precedent of an affiliation with a particular workplace. Because vocational identification develops prior to workplace identity, when professionals leave a job for another employer, they should sustain their professional affiliation. This latter assertion is uncontroversial; the former is open to question. In 
the German VET setting, apprentices in a dual system likely develop their vocational identity while working for a company. For apprentices, after they begin working, their workplace likely shapes their vocational identity as they experience and perform work associated with the selected vocation, which also has implications for their vocational identity (Hypothesis 4).

Vocational learning theory further posits that different forms of identity related to the vocation or the company increase workplace effort. We define "workplace effort" as the activities and intentional efforts that students/apprentices direct toward work performed within the training company. An increasing body of research focuses on vocational learning as a component of individual efforts to contribute to work-related activities and interactions (e.g., Hodkinson and Hodkinson 2004). However, the relation between workplace identity and workplace effort seemingly has decreased in recent decades (Baruch and Cohen 2007; Cohen 1991; Randall 1990). In the modern, individual-based labor market, companies offer weaker generators of identity or sources of personal commitment (Baruch and Cohen 2007). Therefore, we predict that vocational identity mediates the association between workplace identity and workplace effort, such that vocational identification takes the dominant role (Hypothesis 5). To test this prediction in our statistical analysis, we test vocational identity as a mediator between workplace identity and workplace effort. To operationalize our definition of workplace effort, we asked the apprentices how much effort they expend when contributing to their company's success and how much they try to influence decisions and improve actions to ensure the quality or efficiency of their work.

\section{Vocational identity is closely related to vocational competence}

A successful vocational performance requires not only vocational volition but also cognitive ability. The question here is whether vocational identity is also positively aligned with vocational competence. Vocational learning theory posits that forms of identity shape the quality of learning activities. For example, Baethge and Baethge-Kinsky (1998) and Rauner (2007) depict vocational development as a coherent process of identity and competence development occurring while becoming member of a vocational community. Both studies assume bidirectionality of this relationship. Also, in our background model, vocational competence constitutes another cognitive trait on the personality level and therefore cannot be regarded as unidirectional. Accordingly, we aim to empirically investigate the strength of the interactive relation between the two concepts. We define "competence" in line with Hartig, Klieme and Leutner (2008) as a cognitive disposition that is learnable and focused on a certain field of action (domainspecific). In our research context, the field of action or domain is localized in the activities of commercial vocations. We assume that competence, as a cognitive disposition, influences the solution of domain-specific situations and tasks, so it is therefore reasonable to deduce back from the solving of authentic situations to cognitive structures through adequate item design and psychometric procedures (e.g., Wilson 2008; Shavelson 2008). Because measurement of vocational competencies includes both knowledge and action, the tasks implemented within the competence test focus on at least three competence levels, all aiming at the measurement of vocational expertise (see Greeno et al. 1984): 
1. Conceptual competence corresponds to factual knowledge that can be transmitted into action schemata.

2. Procedural competence subsumes the application of knowledge, that is, how to operate with facts, structures, knowledge nets, and their corresponding elements.

3. Interpretative competence focuses on an interpretation of results and on decision processes.

Together, these competence levels refer to successfully completed, occupation-specific tasks. We implemented this operationalization with 36 test items to determine empirically the relation between vocational identity and vocational competence. Our data set ( $\mathrm{N}=187$ ) included industrial apprentices who were assessed in March 2013 at four German vocational schools. Sample tasks of our instrument can be found in the Additional file 1 .

In summary, our literature review identified several predictors of vocational and workplace identity: (1) a dual versus school-based VET, (2) workplace integration, and (3) a free career choice, as well as two effects: (4) willingness to perform and (5) vocational competence as prerequisites for vocational performance. Our theoretical design further predicts that associations between the characteristics of occupational environments and vocational performance are mediated by the more fundamental motivational qualities of learners' vocational and workplace identities (see Figure 3).

\section{Study design \\ Research questions}

The theoretical outline, according to our background model (Lempert 2009), suggests that vocational identity mediates the effects of occupational environments on vocational performance and therefore potentially provides a rich characterization of how apprentices perceive and act. With the present study, we aim to gain insight into the relevant mechanisms. The focal research questions are as follows:

(1)How structurally valid and reliable are the derived measurements of our theoretically outlined definitions?

(2)How do the characteristics of vocational training, specifically, (a) dual versus school-based training, (b) integration in workplaces, and (c) a free career choice, predict vocational and workplace identity?

(3) How do vocational and workplace identities mediate the relationship of the predictive variables with workplace effort?

(4)Is there a detectable relation between vocational identity and vocational competence? More precisely, do apprentices who identify to a greater extent with their occupation or company also achieve higher scores in objective competence tests of their vocational expertise?

\section{Sample characteristics}

The data, gathered in July 2012, comprise a sample of $\mathrm{N}=504$ learners in the middle of their vocational education as industrial clerks. To compare apprentices working in a dual system against students engaged in school-based training, 290 of the participants 
were undergoing a dual and 214 a school-based VET. In total, $55 \%$ of the survey participants were women, and $47 \%$ of the students had a migrational background. However, neither gender nor migrational background correlated with the variables featured in our analysis, so we did not control for them. To research the relation between vocational identity and vocational competence, we conducted objective competence tests empirically of $\mathrm{N}=187$ industrial apprentices in March 2013 at four vocational schools (Munich, Hanover, Bielefeld, and Paderborn). 47 of the apprentices were tested after 1.5 years and 140 apprentices after 2.5 years of their vocational training. The test took 125 minutes, including the test instruction (10 minutes) and completion of the identity survey (10 minutes).

\section{Instruments}

The paper-and-pencil survey consisted of two sections. First, 11 items referred to socioeconomic and biographical information. Second, 14 items measured the indirectly observable constructs of vocational identity, workplace identity, and workplace effort. Our scale development for these items was informed by Blau (1988), Carson and Bedeian (1994), and Heinemann and Rauner (2008). Participants were instructed to give answers that reflected their personal perceptions, using five-point Likert scales, from $1=$ "I do not agree" to 5 = "I totally agree." Thus, higher scores indicated a higher value for the related construct. The competence test comprised 36 items depicting knowledge and ability in the area of business and commerce. The item responses were scaled using a correction scheme ( 0 = "incorrect or no solution," $1=$ "partial solution," and $2=$ "correct solution"). The responses were then combined into one factor value for each participant. The respondents participated voluntarily during both data collections, through an agreement with their teachers and the schools' executive boards.

\section{Method}

To begin our data analysis, we evaluated the measurement instrument. An exploratory factor analysis validated the survey's factorial structure. The data seemed appropriate for factor analyses $(\mathrm{KMO}=.89$; Bartlett test $=.00)$, so we conducted an analysis with the Kaiser criterion and a parallel assessment (Horn 1965) to identify the number of latent constructs in the database. Structural equation modeling (SEM) in AMOS served to align the measurement models with the hypothesized relations of the study constructs. Missing data were addressed through full-information maximum likelihood estimation (FIML); several simulation investigations affirm that FIML outperforms most other common methods of handling missing data (Baraldi and Enders 2010; Enders and Bandalos 2001). To address the research questions, we fit baseline models of the direct effects of the four independent variables on the latent factor constructs. After establishing these direct relationships, we introduced vocational identity and workplace identity as mediators of vocational performance and tested the mediating effects. Specifically, we estimated indirect effects with delta method standard errors to confirm the mediation (MacKinnon et al. 2002; Sobel 1982). To test Hypothesis 6, we built a mere factor score for the competence test and conducted a bivariate correlation analysis with the constructs in our identity survey. 


\section{Results}

\section{Measurement model}

As a result of an analysis with the Kaiser criterion and a parallel assessment (Horn 1965), the survey items indicated a three-factor solution. Figure 4 presents the results graphically.

The empirical factor analysis of our survey instrument led to the theoretically assumed structure in which vocational identity, workplace identity, and workplace effort are empirically separate concepts. The three concepts explain $62 \%$ of the total variance and affirm strong internal consistency (Cronbach's $\alpha \mathrm{s}$ : factor $1=.83$; factor $2=.90$; factor $3=.71$ ). This three-dimensional structure also received confirmation in a confirmatory factor analysis in AMOS; the three-factor measurement model fit the data significantly better (.000) than a two- or one-factor model. ${ }^{\mathrm{b}}$ Table 1 presents all the questions from the measurement instrument and contains the respective factor coefficients and R-square values.

The formulated items and derived instrument thus can measure vocational identity appropriately, in terms of factorial validity and reliability. All variables had low to moderate correlations (.07 to .57), suggesting little multicollinearity. Therefore, we conclude that the instrument is applicable for testing the hypotheses regarding the influences on and effects of vocational identity. Table 2 provides the correlations among the generated factors.

\section{Directly fitted path model}

The standardized path coefficients for the directly fitted model are depicted in Figure 5. Integration at the workplace was positively associated with workplace identity $(r=.42)$, workplace effort $(r=.41)$, and, to a lesser extent, vocational identity $(r=.28)$. From a biographical perspective, students who decided voluntarily on their vocation were more likely to develop workplace (.34) and vocational (.52) identity and to perform effortfully (.29). In summary, the model accounts for $31 \%$ of the variance in workplace effort, $37 \%$

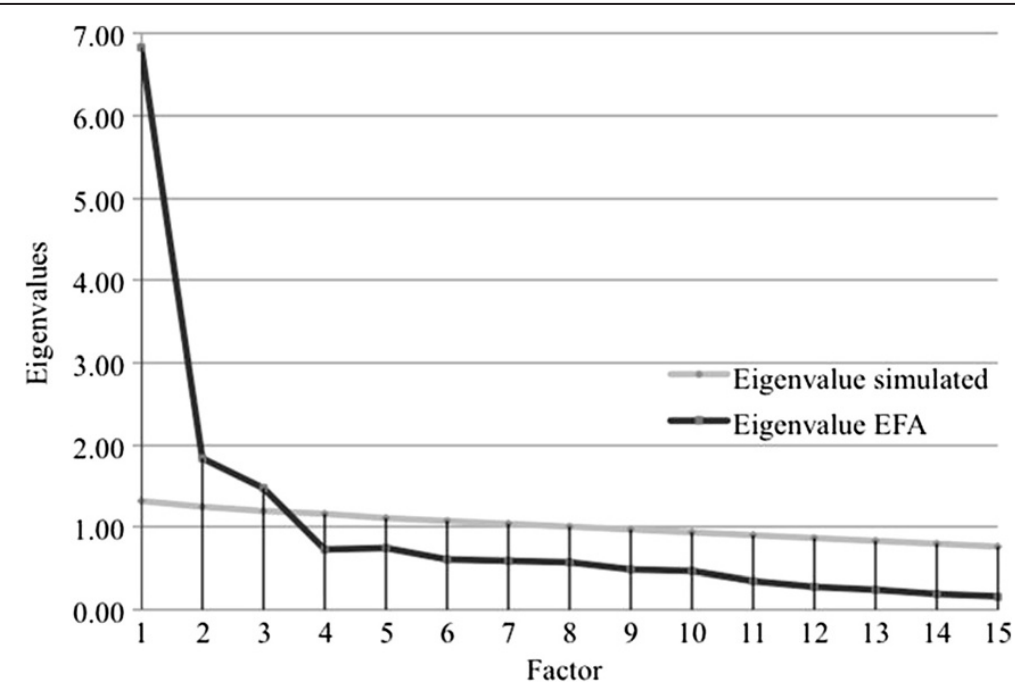

Figure 4 Factor extraction. 
Table 1 Empirical fit of items measuring vocational identity

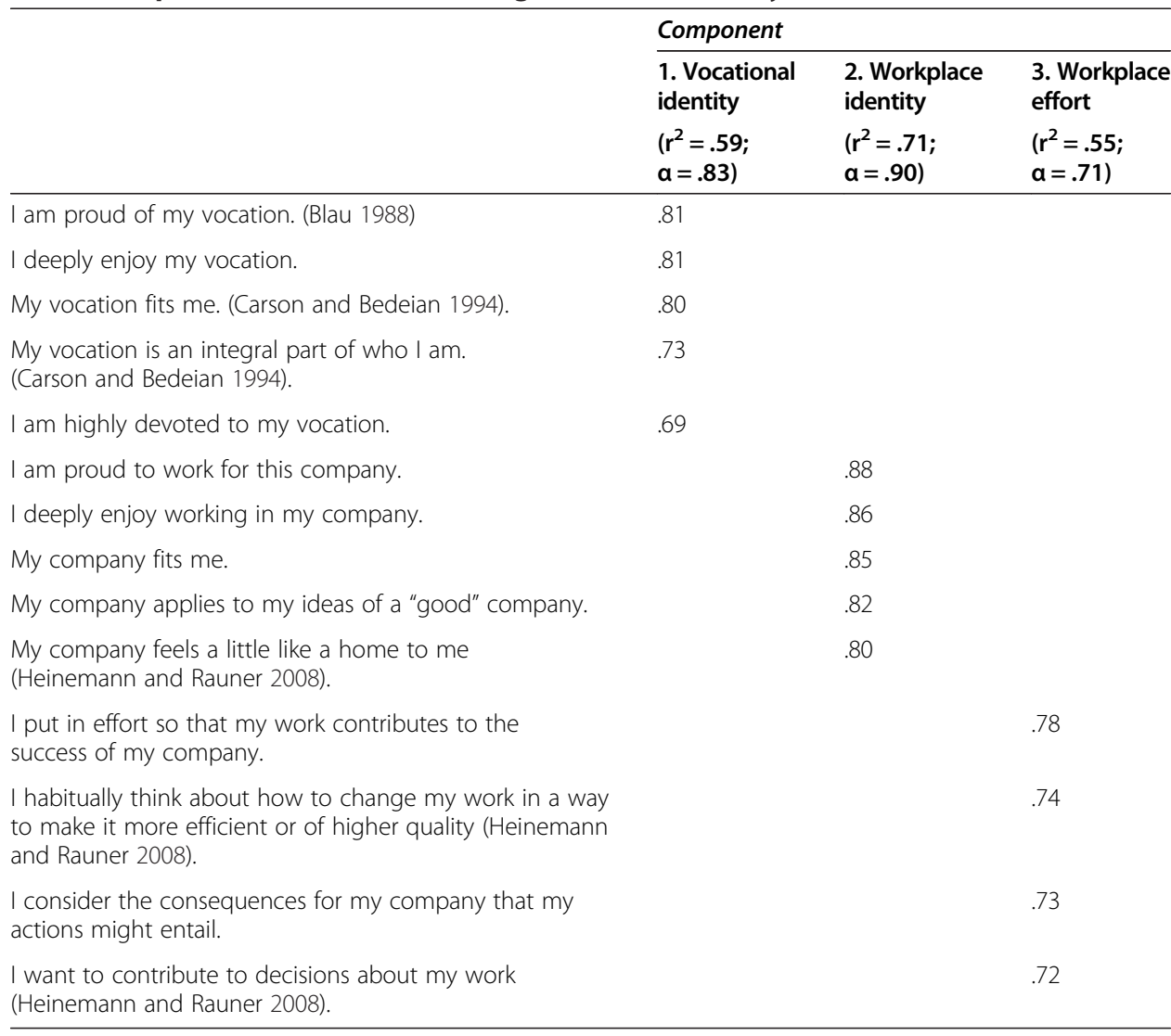

in workplace identity, and $38 \%$ of the variance in vocational identity. However, the overall model fit is poor $\left(\mathrm{x}^{2} / \mathrm{df}=9.999, p=.000\right.$; comparative fit index $[\mathrm{CFI}]=.882$; root mean square error of approximation $[$ RMSEA $]=.134)$.

\section{Mediated path model}

Modeling vocational identity as a mediator between workplace identity and workplace effort significantly improved the overall model fit $\left(\mathrm{X}^{2} / \mathrm{df}=1.300, p=.272\right.$; CFI $=.998$; RMSEA $=.024)$. Regarding causality, we determined that the model predicting an effect

Table 2 Means, standard deviations, and intercorrelations among all relevant variables

\begin{tabular}{lllllll}
\hline & $\mathbf{1 .}$ & $\mathbf{2 .}$ & $\mathbf{3 .}$ & $\mathbf{4 .}$ & $\mathbf{5 .}$ & $\mathbf{6 .}$ \\
\hline 1. Vocational identity & 1 & & & & & \\
2. Workplace identity & $.57^{* * *}$ & 1 & & & \\
3. Workplace effort & $.39^{* * *}$ & $.34^{* * *}$ & 1 & & \\
4. Workplace integration & $.36^{* * *}$ & $.38^{* * *}$ & $.36^{* * *}$ & 1 & \\
5. Free career choice & $.59^{* * *}$ & $.45^{* * *}$ & $.37^{* * *}$ & $.33^{* * *}$ & 1 & \\
6. Dual versus school-based VET & $.14^{* *}$ & - & - & - & .07 & 1 \\
M & 3.62 & 3.65 & 3.97 & 3.94 & 3.44 & .41 \\
SD & 1.05 & 1.02 & 0.87 & .86 & 1.17 & .49 \\
\hline${ }^{*} p<.05 .{ }^{* *} p<.01 .{ }^{* * *} p<.001$. & & & & & &
\end{tabular}

${ }^{*} p<.05 .{ }^{* *} p<.01{ }^{* * *} p<.001$. 


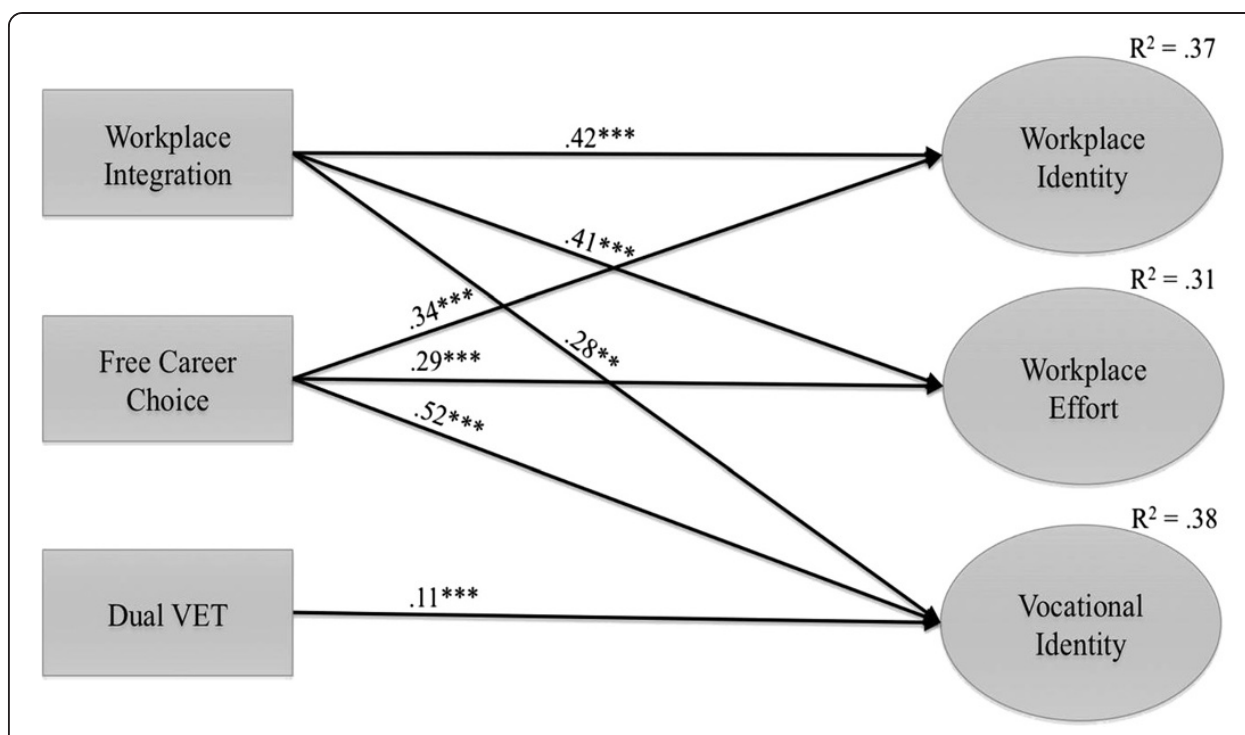

Figure 5 Directly fitted path model with direct effects of indicator variables on all latent factors.

of workplace identity on vocational identity fit the data significantly better than a model with the opposite effect (.000), in support of Hypothesis $4^{\mathrm{C}}$. We present the standardized path coefficients for the mediated model in Figure 6. We excluded the significant direct effects between the independent variables and vocational engagement from the model for clarity; Table 3 presents these values.

The group variable, indicating dual versus solely school-based VET, had a significant though small effect on vocational identity $(r=.09)$. The effect of workplace identity on workplace effort was partially mediated by vocational identity $(\mathrm{r}=.10)$. Although the direct effect of workplace identity on vocational identity was strong (.49), its direct effect on workplace effort decreased and became quite small $(r=.08)$ when we allowed the mediation through vocational identity. The effect of free career choice on workplace effort was partially mediated by vocational identity and workplace identity $(r=.14)$; it also had a direct effect on workplace effort $(r=.16)$, workplace identity $(r=.38)$, and vocational identity $(r=.35)$. However, the effect of workplace integration on vocational identity

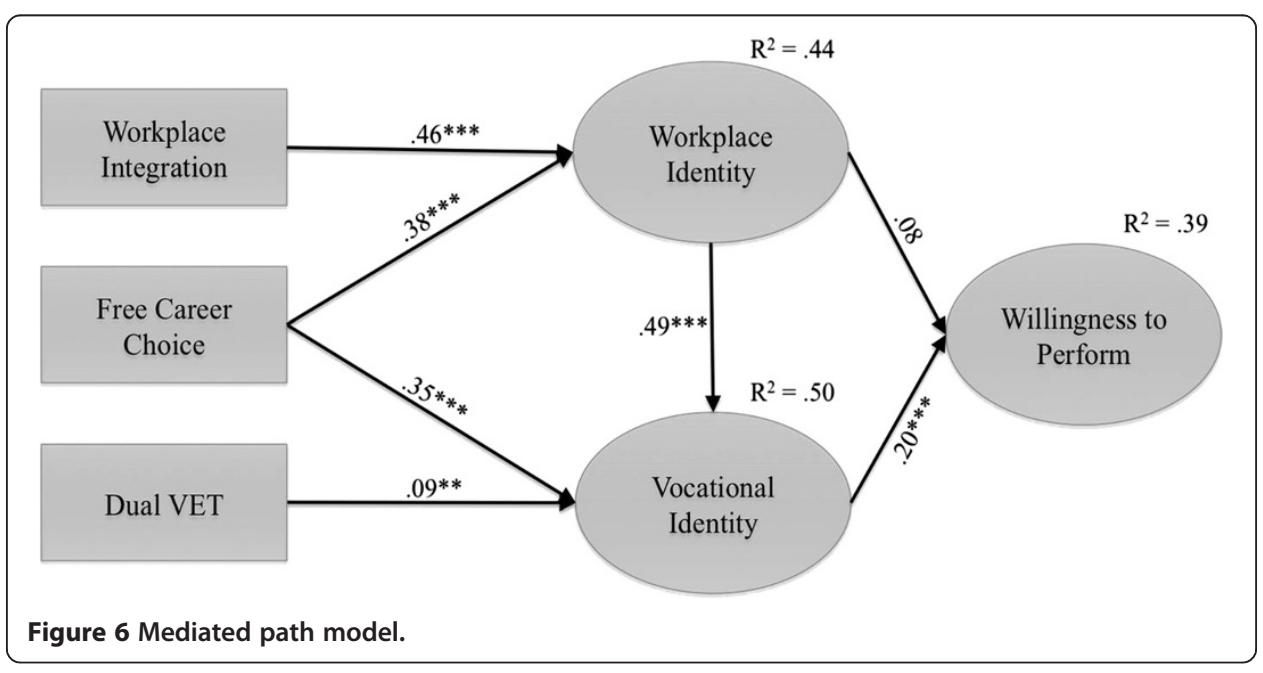


Table 3 Standardized direct, indirect, and total effects for mediated relations

\begin{tabular}{llll}
\hline Predictor, mediator & Workplace effort & & Total \\
\cline { 2 - 4 } & Direct & Indirect & $.18^{* *}$ \\
\hline P: Workplace identity & .08 & - & - \\
M: Vocational identity & $.20^{* * *}$ & & Total \\
& Workplace effort & Indirect & $.45^{* * *}$ \\
P: Workplace integration & Direct & .08 & - \\
M: Workplace identity & $.37^{* * *}$ & - & \\
& .08 & & Total \\
P: Free career choice & Workplace Effort & Indirect & $.30^{* * *}$ \\
M: Vocational identity & Direct & $.14^{* *}$ & - \\
M: Workplace identity & $.16^{*}$ & - & - \\
\hline
\end{tabular}

was not significantly mediated by workplace identity $(r=.08)$. Instead, workplace integration directly increased both workplace identity $(\mathrm{r}=.46)$ and workplace effort $(\mathrm{r}=.37)$. Including the mediating variables added $8 \%, 12 \%$, and $7 \%$ to the explained variance, yielding overall explanations of $39 \%, 50 \%$, and $44 \%$ of the variance of vocational identity, workplace identity, and workplace effort, respectively.

For the relation between vocational identity and the vocational competence of the apprentices, we found an effect of $r=.25$ in support of Hypothesis 6 (Table 4). Vocational identity further correlates with the average grade obtained at the vocational school $(\mathrm{r}=.15)$ and the apprentices' self-rating of their vocational competence $(\mathrm{r}=.24)$. (We measured this self-rating on a six-point scale, in line with the German grading system.) Workplace identity correlates to a lesser extent with the competence tests $(\mathrm{r}=.14)$ and the apprentices' self-rating of their vocational competence $(\mathrm{r}=.16)$. The competence tests correlate fairly well with the average grade given by the vocational school teachers $(\mathrm{r}=.40)$ and with the apprentices' self-rating of their vocational competence $(r=.33)$, suggesting high retrograde and concurrent validity of the competence measure.

\section{Discussion}

Our study of vocational identity as a personal concept, arising through interactions between the person and the mode of VET, features tests of six theoretical hypotheses

Table 4 Correlation analysis of the relation between vocational identity and vocational competence

\begin{tabular}{|c|c|c|c|c|c|}
\hline & 1. & 2. & 3. & 4. & 5. \\
\hline 1. Vocational identity & 1 & & & & \\
\hline 2. Workplace identity & $.53 * * *$ & 1 & & & \\
\hline 3. Self-rating of vocational competence & $.24^{* * *}$ & $.16^{*}$ & 1 & & \\
\hline 4. Competence test & $.25^{* * *}$ & $.14^{*}$ & $33^{* * *}$ & 1 & \\
\hline 5. Vocational school grades & $.15^{*}$ & .04 & $.48^{* * *}$ & $.40^{* * *}$ & 1 \\
\hline
\end{tabular}


about the genesis and effects of vocational identity. We discuss the results in the following subsections.

\section{Hypothesis 1}

In our quantitative, empirical model, we first predict that vocational identity can be fostered more effectively through continuous workplace learning experiences, which can be implemented with dual VET (Kirpal 2006). We find only a minor, albeit stable, effect in support of this prediction: Students who spend half their study time in workplace environments tend to identify slightly more strongly with their occupation than students who study only in a school setting. However, one might expect a higher group effect; theoretically, students without workplace experience cannot build a vocational identity, because they have never engaged in the occupational practice or with its practitioners. Therefore, we suggest that the issue of whether scholastic or dual apprentices identify more strongly with the occupation might be not the right question: $27 \%$ of scholastic learners stated in our context survey that they had already gathered practical experience in the business and commerce sector through pertinent internships. This finding indicates that our dummy variable of a dual versus solely school-based training does not adequately capture the amount of practical training a learner underwent. Comparing learners with practical experience (scholastic learners with prior pertinent internships or dual apprentices with continuous working experience) versus learners with no practical experience generates an effect of .19. Therefore, the amount of practical training might be a more precise predictor of vocational identity than dual versus solely school-based training.

\section{Hypothesis 2}

Integrating vocational apprentices into organizational work processes strongly increases apprentices' workplace identity and has a direct effect on their workplace effort. Positive cooperation with apprentices requires their effective engagement in work groups, in support of the concept of enhanced participatory practices and enculturation (Lave and Wenger 1991). Vocational learning is a situated activity that takes place through a process of engagement in the sociocultural practices of the workplace. Chan (2011) similarly describes how bakers progress in their vocational identity, such that they first sense belonging to a particular bakery and demonstrate competence before they go on to identify as a baker. The first step is contingent on the degree to which they are accepted, recognized, and granted discretion as an apprentice in the workplace where they apprenticed.

\section{Hypothesis 3}

We proposed and found a strong, significant influence of free career choice on both vocational identity and workplace identity. In addition, free career choice appeared to have a direct impact on workplace effort. Students voluntarily deciding on their vocational training identify more strongly with and engage more effortfully in their selected occupation. This finding is consistent with Heinemann et al.'s (2009) recognition of a positive correlation between vocational identity and free career choice $(r=.27)$ across 23 VET programs. We thus confirm Hypothesis 3. 


\section{Hypotheses 4 and 5}

For Hypothesis 4, we tested the causal relation between workplace and vocational identity. On the basis of theoretical considerations, we predicted an influence of workplace identity on vocational identity; this direction was empirically confirmed, such that this causal relation appears more likely among young apprentices. However, for advanced workers at later stages of their careers, or for those starting in a new company, the direction of the causal effect may switch, because they already have acquired a distinct, stable vocational identity that can shape the development of their new workplace identity when they move to a new work environment. The empirical results related to Hypothesis 5 suggest that workplace identity is not as prominent a source of workplace effort as vocational identity. Instead, much of the total influence of workplace identity on workplace effort is mediated by the more general concept of vocational identity.

\section{Hypotheses 6}

Regarding Hypothesis 6, the theoretically postulated alignment between vocational identity and vocational competence is upheld. Vocational identity correlates fairly well with our developed competence tests, as well as with grades given by vocational teachers and with apprentices' self-rated vocational competence.

In summary, two conditions seem required to trigger identity and excellence. First, apprentices must be granted practical experience; during that experience, they must be welcomed and invited to participate in all operating work processes. Second, the apprentices themselves must voluntarily participate to be able to accept this invitation and decide to engage. The effects of the influencing factors on vocational performance are mediated by a personal identity conception (Allan 2005; Billett and Pavolva 2005; Etelpäpelto 2008; Fenwick 2004; Somerville and Abrahamsson 2003).

\section{Conclusions and limitations}

Our results highlight that several VET characteristics exert important influences on vocational and workplace identity. We find that functional integration at the workplace (Billett 2004; Chan 2011; Hartigan-Rogers et al. 2007; Henderson et al. 2007; Lave and Wenger 1991; Newton et al. 2009), free career choice (Bühler 2007; Heinemann et al. 2009), and practical experience (Billett and Somerville 2004) foster the development of vocational identity. The mediation analyses demonstrate that learners' vocational and workplace identities, as a form of intrinsic motivation, strengthen the relationships between VET characteristics and the apprentice's willingness to perform, as Rauner (1999) suggests. These conclusions match Billett's (2011) view of workplace affordances and individual bases of engagement as means to understand the duality by which learning arises through work participation. We also show that vocational identity is not only central to vocational volition but also aligned with the development of vocational competence, as Baethge and Baethge-Kinsky (1998) and Rauner (2007) suggest. We therefore conclude from our analyses that vocational identity constitutes a crucial factor for the development of an excellent workforce, in that it fosters employees' willingness to perform in work settings and is closely related to vocational competence. We further suggest that vocational instructors have critical roles in terms of creating positive 
vocational learning environments in schools and workplaces that can optimize learners' perceptions of their occupations in practice, thereby shaping vocational identity, which then increases competence and willingness to perform. In line with our model results, we outline three points of intervention to strengthen a learner's vocational identity and thereby optimize VET:

\section{(1) Grant vocational learners an opportunity to experience actual work.}

Vocational theory suggests that learners cannot form worthwhile, robust vocational identities without experiencing work and without actively engaging and learning in workplaces. Yet fewer firms seem willing or able to provide apprenticeship experience, which suggests the need for other options. Our results suggest that the amount of practical training is a more stable predictor of vocational identity than dual versus solely school-based training; therefore, we recommend that providing vocational internships can improve learners' identification with their vocation and potentially overcome differences between scholastic learners and apprentices. At a policy level, governments could cooperate with the private business sector to either train more apprentices or implement more internships as an integral part of vocational school policies.

(2) Ensure maximum integration at the workplace for apprentices. Apprentices need support as they develop their sense of self as workers, through enhanced participatory practices afforded by workplaces. Our results suggest that by being allowed to participate in all operating processes, they more readily develop vocational identity and apply more workplace effort. Therefore, apprentices need opportunities for active, productive participation in work processes, rather than just taking observational roles or performing isolated, monotonous work. These practices often occur already, but this emphasis should become a central motif for securing the development of vocational identity and capacities.

(3) Make vocational training consonant with individual workers' agency. Free career choice is not only desirable for its own sake; it also encourages the development of a highly identified workforce. Our results emphasize the importance of individual interest in and consent to engage fully in the process of occupational preparation. Thus, personal and social efficiency likely can be fostered by a society's "cultivation of power to join freely and fully in shared or common activities" (Dewey 1916, p. 85). In this respect, vocational education inhabits an important role or responsibility: to assist young people in their efforts to identify the vocation for which they are best suited and to which they are drawn. Policies and practices associated with securing occupation must consider individual agency if the goal is to achieve high engagement and effective learning outcomes.

We note several shortcomings in our study approach. The measurement of vocational identity relies on self-reports to assess students' identity concepts and work effort. This approach raises important validity concerns, in that students could offer what they perceive to be socially desirable answers. Moreover, the self-reports between the scholastic learners and dual apprentices might be biased by selection effects not captured within our data, as the scholastic system usually comprises young people who did not succeed in entering a regular training system due to a lower class rank in prior 
schooling and/or poor grades. If these variables influence the fostering of vocational identity, the effect we found might deviate from our results. Another issue resides in our objective competence test for testing Hypothesis 6 (written examination). The items are designed to capture knowledge and capability regarding the expertise of the apprentices. However, they do not capture other relevant facets such as social competence, which is a key factor in handling social interaction processes. We checked our competence tests for retrograde and concurrent validity but not for prognostic validity. Further research should investigate if the measured ability, in the sense of a disposition for expertise, also predicts the actual performance of the apprentices observed at the workplace, as captured through expert evaluations for example. Finally, with regard to the relation between vocational identity and vocational competence, we assumed a mutually reinforcing relation, in line with Baethge and Baethge-Kinsky (1998) and Rauner (2007). However, there is no clear theoretical rationale of antecedents and consequences regarding this relationship. Longitudinal research is needed to address this question empirically. Therefore, research endeavors should apply the developed identity instrument over the duration of vocational training, combined with competence tests to explicitly test causalities.

\section{Endnotes}

aThe term "transitional system" can be misleading, because no systematic organizational structure guarantees a transition. Instead, it encompasses various training, education, and labor market schemes provided by governmental bodies to engage young people who did not enter a regular training system (Baethge et al. 2007).

bone-factor model: $\mathrm{N}=504: \mathrm{X} / \mathrm{df}=7.26, \mathrm{X}^{2}=559.192$ and $\mathrm{df}=77$; two-factor-model: $\mathrm{N}=504: \mathrm{X}^{2} / \mathrm{df}=5.60, \mathrm{X}^{2}=425.741$ and $\mathrm{df}=76$; three-factor-model: $\mathrm{N}=504: \mathrm{X}^{2} / \mathrm{df}=4.17$, $\mathrm{X}^{2}=308.681$ and $\mathrm{df}=74$.

${ }^{\mathrm{c}}$ Model 1 (workplace identity $\rightarrow$ vocational identity): $\mathrm{x} 2 / \mathrm{df}=1.300$; Model 2 (vocational identity $\rightarrow$ workplace identity): $\chi^{2} / \mathrm{df}=4.069$.

\section{Additional file}

Additional file 1: Sample tasks.

Competing interests

The authors declare that they have no competing interests.

\section{Authors' contributions}

All authors contributed substantially to this work. VKK designed the study and analysed the data; SB contributed to the theoretical framework and helped to draft the manuscript. EW participated in the coordination of the study and helped to draft the manuscript. All authors participated in discussing the manuscript at all stages. All authors read and approved the final manuscript.

\section{Acknowledgement}

This article arose from the subproject "Competence-oriented assessments in VET and professional development" (Wi 3597/1-1 and Wi 3597/1-2), within the framework of the priority programme "Competence Models for Assessing Individual Learning Outcomes and Evaluating Educational Processes" (SPP 1293) of the German Research Foundation (DFG).

\section{Author details}

${ }^{1}$ Chair of Business and Human Resource Education, University of Paderborn, Warburger Straße 100, D-33098, Paderborn, Germany. ${ }^{2}$ School of Education and Professional Studies, Griffith University, 170 Kessels Road, Nathan, QLD 4111, Australia. 
Received: 21 November 2013 Accepted: 31 March 2014

Published online: 25 April 2014

\section{References}

Achtenhagen F (2004) Prüfung von leistungsindikatoren für die berufsbildung sowie zur ausdifferenzierung beruflicher kompetenzprofile nach wissensarten. BMBF, Bonn

Aldrich R (1994) Vocational education in Britain: An historical and cultural analysis. In: Heikkinen A (ed) Vocational education and culture: European prospects from history and life history. University of Tampere, Tampere, Finland

Allan JK (2005) Farmers as learners: evolving identity, disposition and mastery through diverse practices. Rural Sociol 15(1):4-21

Anderson D (1998) Successful reform: Reframing the national VET policy agenda. In: Ferrier F, Anderson D (ed) Different drums one beat? Economic and social goals in education and training (pp 60-75). National Centre for Vocational Educational Research, Adelaide, Australia

Aranya N, Polluck J, Amernic J (1981) An examination of professional commitment in public accounting. Account Org S 6:271-280

Ashton D, Green F (1996) Education, training and the global economy. Edward Elgar, London

Baethge M, Arends L (2009) Feasibility study VET-LSA: A comparative analysis of occupational profiles and VET programmes in 8 European countries. BMBF, Göttingen

Baethge M, Baethge-Kinsky V (1998) Jenseits von Beruf und Beruflichkeit? Neue Formen von Arbeitsorganisation und Beschäftigung und ihre Bedeutung für eine zentrale Kategorie gesellschaftlicher Integration. Mitt Arbeitsmarkt Berufsforsch 31(3):461-472

Baethge M, Solga H, Wiek M (2007) Berufsbildung im umbruch: Signale eines überfälligen aufbruchs. Friedrich-Ebert-Stiftung, Berlin

Baethge M, Arends L, Winther E (2009) International large-scale assessment on vocational and occupational education and training. In: Oser F, Renold U, John EG, Winther E, Weber S (ed) VET Boost: Towards a Theory of Professional Competencies (pp 3-24). Sense Publishers, Rotterdam

Baraldi AN, Enders CK (2010) An introduction to modern missing data analyses. J School Psychol 48(1):5-37

Baruch Y, Cohen A (2007) The dynamics between organisational commitment and professional identity formation at work. In: Brown A, Kirpal S, Rauner F (ed) Identities at work. Springer, Dordrecht

BBG (2002) Berufsbildungsgesetz. Bundesversammlung der Schweizerischen Eidgenossenschaft. Bern: Bundesamt für Bauten und Logistik (BBL)

Billett S (2004) Learning through work: Workplace participatory practices. Routledge, London

Billett S (2006) Work, change and workers. Springer, Dodrecht

Billett S (2011) Vocational education: Purposes, traditions and prospects. Springer, Dodrecht

Billett S, Pavolva M (2005) Learning through working life: Self and individuals' agentic action. Int J Lifelong Ed 24(3):195-211

Billett S, Somerville M (2004) Transformation at work: identity and learning. Stud Cont Ed 26(2):309-326

Blau G (1988) Management and prediction of career commitment. J Occup Psychol 32(85):227-288

BMBF (ed) (2012) Bildung in Deutschland 2012 - Ein indikatorengestützter Bericht mit einer Analyse zur kulturellen Bildung im Lebenslauf. Bertelsmann, Bielefeld

Boekaerts M (2002) Bringing about change in the classroom: strengths and weaknesses of the self-regulated learning approach. Learn Instr 12:589-604

Bourdieu P (1990) The logic of practice. Polity Press, Cambridge

Bühler C (2007) Zwischen Flexibilität und Resignation. Berufliche Identität junger Erwerbstätiger. In: Mansel J, Kahlert H (ed) Arbeit und Identität im Jugendalter. Die Auswirkungen der gesellschaftlichen Strukturkrise auf Sozialisation. Juventa, Weinheim München, pp 33-47

Butler E (2000) Knowing "now", learning futures: the politics and knowledge practices of vocational education and training. Int J Lifelong Ed 19(4):322-341

Carson KD, Bedeian AG (1994) Career commitment: construction of a measure and examination of its psychometric properties. J Vocat Behav 44(3):237-262

Chan S (2011) Belonging, becoming and being: First-year apprentices' experiences in the workplace. Ako Aotearoa, Wellington, New Zealand

Chomsky N (1981) Lectures on government and binding. Foris, Dordrecht

Cohen A (1991) Career stage as a moderator of the relationships between organizational commitment and its outcomes: A meta-analysis. J Occup Psych 64(1):253-268

Corsten M, Lempert W (1992) Moralische dimensionen der arbeitssphäre. Literaturbericht, fallstudien, und bedingungsanalysen zum betrieblichen und beruflichen handeln und lernen. Max-Planck-Institut für Bildungsforschung, Berlin

Côté JE, Levine CG (2002) Identity formation, agency, and culture: A social psychological synthesis. Lawrence Erlbaum, Mahwah, NJ

Dewey J (1916) Democracy and education. Free Press, New York

Drexel I (2005) Das duale system und Europa. Ein gutachten im auftrag von. VER.DI und IG-Metall, Verdi, Berlin

Dror Y (1993) Policy professionalism as a vocational calling. Policy Stud J 21(1):6-13

Enders CK, Bandalos DL (2001) The relative performance of full information maximum likelihood estimation for missing data in structural equation models. Struct Equ Model 8(3):430-457

Estola E, Erkkilä R, Syrjälä L (2003) A moral voice of vocation in teacher's narratives. Teach Teach 9(3):239-256

Eteläpelto A (2008) Perspectives, prospects and progress in work-related learning. In: Billett S, Harteis C, Eteläpelto A (ed) Emerging perspectives of workplace learning (pp 233-247). Sense, Rotterdam

Fenwick T (2004) Learning in portfolio work: anchored innovation and mobile identity. Stud Cont Ed 26(2):229-246

Greeno JG, Riley MS, Gelman R (1984) Conceptual competence and children's counting. Cog Psy 16:94-143

Haasler B (2007) Apprentices' experiences of occupational and organisational commitment: An empirical investigation in a German automobile company. In: Brown A, Kirpal S, Rauner F (ed) Identities at work. Springer, Dordrecht, pp 261-284

Hansen DT (1994) Teaching and the sense of vocation. Ed Theory 44(3):259-275 
Hartig J, Klieme E, Leutner D (ed) (2008) Assessment of competencies in educational Contexts: State of the art and future prospects. Hogrefe Huber, Göttingen

Hartigan-Rogers JA, Cobbett SL, Amirault MA, Muise-Davis ME (2007) Nursing graduates' perceptions of their undergraduate clinical placement. Int I Nurs Educ Scholarsh 4:1-12

Heinemann L, Rauner F (2008) Identität und engagement: Konstruktion eines instruments zur beschreibung der Entwicklung beruflichen engagements und beruflicher Identität. A+B Forschungsberichte 1:1-24

Heinemann L, Maurer A, Rauner F (2009) Engagement und ausbildungsorganisation. In: Einstellungen Bremerhavener Auszubildender zu ihrem Beruf und ihrer Ausbildung. Industrie- und Handelskammer Bremerhaven, Bremen

Henderson S, Happell B, Martin T (2007) So what is so good about clinical experience? A mental health nursing perspective. Nurse Educ Prac 7(3):164-172

Hodkinson PM, Hodkinson HD (2004) The significance of individuals' dispositions in workplace learning: a case study of two teachers. J Ed Work 17(2):167-182

Horn JL (1965) A rationale and test for the number of factors in factor analysis. Psychometrika 30:179-185

House JS (1977) The three faces of social psychology. Sociometry 40:161-177

Kantor H (1986) Work, education, and vocational reform: the ideological origins of vocational education, 1890-1920. Amer J Educ 94(1):401-426

Kirpal S (2006) Arbeitsidentitäten in vergleichenden perspektiven: die rolle der nationalen und sektoralen kontextvariablen. Europäische Zeitschrift für Berufsbildung 39(3):26-54

Kroger J (1993) On the nature of structural transition in the identity formation process. In: Kroger J (ed) Discussions on ego identity. Lawrence Erlbaum, Hillsdale, NJ

Kutscha G (2000) General education and initial vocational training in Germany: The "flexicurity route" of modernization under aspects of flexibility, transferability and mobility. Contribution to COST A11, working group1: VET policy. Georg-August-University Göttingen, Septermber 21th-24th

Lave J, Wenger E (1991) Situated learning: Legitimate peripheral participation. Cambridge University Press, Cambridge

Lee K, Carswell JJ, Allen NJ (2000) A meta-analytic review of occupational commitment: relations with person-and work-related variable. J Appl Psychol 85:799-811

Lempert W (2009) Berufliche Sozialisation. Persönlichkeitsentwicklung in der betrieblichen Ausbildung und Arbeit. Schneider, Blatmannsweiler

Lent RW, Brown SD, Hackett G (2000) Contextual supports and barriers to career choice: a social cognitive analysis. J Couns Psychol 47(1):36-49

Mackinnon DP, Lockwood CM, Hoffman JM, West SG, Sheets V (2002) A comparison of methods to test mediation and other intervening variables effects. Psychol Methods 7(1):83-104

Marsh HW, Shavelson RJ (1985) Self-concept: its multifaceted, hierarchical structure. Educ Psychol 20:107-125

Mead GH (1934) Mind, self, and society from the standpoint of a social behaviorist. University of Chicago Press, Chicago

Newton J, Billet S, Ockerby C (2009) Journeying through clinical placements: An examination of six student cases. Nurse Educ Today 29(6):1231-1237

Peiperl MA, Baruch Y (1997) Back to square zero: the post-corporate career. Organ Dyn 25(4):7-22

Pellegrino JW, Chudowsky N, Glaser R (2001) Knowing what students know: The science and design of educational assessment. National Academies Press, Washington, DC

Randall DM (1990) The consequences of organizational commitment: methodological investigation. J Organ Behav 11:361-378

Rauner $F$ (1999) Entwicklungslogisch strukturierte berufliche curricula: Vom neuling zur reflektierten meisterschaft. Zeitschrift für Berufs- und Wirtschaftspädagogik 95(3):424-446

Rauner F (2007) Vocational education and training: A European perspective. In: Brown A, Kirpal S, Rauner F (ed) Identities at work (pp 115-144). Springer, Dodrecht

Renold U (2009) Developing sustainable VET/PET research in Switzerland: An approach combining research, policymaking and practice. In: Oser F, Renold U, John EG, Winther E, Weber S (ed) VET boost: Towards a theory of professional competencies (pp 101-110). Sense Publishers, Rotterdam

Searle JR (1995) The construction of social reality. Penguin, London

Shavelson RJ (2008) Reflections on quantitative reasoning: An assessment perspective. In: Madison BL, Steen LA (ed) Calculation vs. context: Quantitative literacy and its implications for teacher education. Mathematical Association of America, Washington DC, pp 27-47

Shavelson RJ, Ruiz-Primo M (2005) Windows into the mind. Int J Higher Education Educ Plan 48(1):413-430

Skorikov VB, Vondracek FW (1998) Vocational identity development: its relationship to other identity domains and to overall identity development. J Career Assessment 6:13-35

Skorikov VB, Vondracek FW (2007) Positive career orientation as an inhibitor of adolescent problem behavior. Journal of Adolescence 30:131-146

Sobel ME (1982) Asymptotic intervals for indirect effects in structural equations models. In: Leinhart S (ed) Sociological methodology (pp 290-312). Jossey-Bass, San Francisco

Solomontos-Kountouri O, Hurry J (2008) Political, religious and occupational identities in context: challenging identity status paradigm. J Adolescence 31(2):241-258

Somerville M (2006) Subjected bodies, or embodies subjects: Subjectivity and learning safety at work. In: Billett S, Fenwick T, Somerville M (ed) Work, subjectivity and learning (pp 37-52). Springer, Dodrecht

Somerville M, Abrahamson L (2003) Trainers and learners constructing a community of practice: masculine work cultures and learning safety in the mining industry. Stud Ed Adults 35(1):19-34

Wallace JE (1993) Professional and organizational commitment: compatible or incompatible? J Vocat Behav 42:333-349

Wilson M (2008) Cognitive diagnosis using item response models. J Psychol 216(2):74-88

doi:10.1186/s40461-014-0006-0

Cite this article as: Klotz et al:: Promoting workforce excellence: formation and relevance of vocational identity for vocational educational training. Empirical Research in Vocational Education and Training 2014 6:6. 